\title{
PERCEPTION OF HOME-SHARING INDUSTRY: A STUDY OF COMPARING AIRBNB AND COUCHSURFING
}

\author{
JinTao Huang, KangNyeon Yi and JiHye Han \\ Department of Interaction Science, SungKyunKwan University, \\ Seoul, South Korea
}

\begin{abstract}
The aim of this paper is to examine people's perceptions of home sharing industry through comparing Airbnb and Couchsurfing, using python to crawling twitter's data. We conducted semantic network analysis by using UCINET, which is embedded with NETDRAW, for calculating betweenness centrality and visualizing semantic network based on multidimensional scaling(MDS). And we also used LIWC to analysis public sentimental perceptions. The present study's results show that the characteristics discovered about Airbnb and Couchsurfing in cyberspace have possible future directions in view of word usage frequency, centrality and semantic networks. Moreover, the results show that in sentimental aspects, there are different public trends of emotions on Airbnb and Couchsurfing. Through those results, researchers provide information to understand which sectors should entrepreneurs put more efforts and money.
\end{abstract}

\section{KEYWORDS}

Sharing Economy, Home-sharing, Airbnb, Couchsurfing, Semantic Network Analysis

\section{INTRODUCTION}

Sharing is a phenomenon as old as humankind, while collaborative consumption and the "sharing economy" are phenomena born of the Internet age (Russell, 2014). The sharing economy is a socio-economic system that coordinates "the peer-to-peer-based activity of obtaining, giving, or sharing the access to goods and services" through "community-based online services" (Hamari et al., 2015). This economy system is a new cooperative production and consumption mode that enables the sharing of various goods and services by virtue of internet. These types of economies have recently become one of the important forms of achieving sustainable development by use of scientific and technological innovations. And especially, we focus on space sharing, which is one of the sharing economy. Space sharing includes releasing the information and prices of idle properties through various platforms on the Internet for tourists, people who are taking business trips, and other people with a need for, or those who are looking for housing, to select (Xinyuea et al., 2016). The home sharing economy already has a foothold in the vacation rental market, which accounted for $9 \%$ of the traditional hotel market in 2014. This market is now becoming more organized and gaining more widespread use as trust in these services increases (Saussier, 2015). 
However, not many sharing economy platforms survive and only a few are economically successful. The success of these platforms in developing from start-ups to sustainable businesses depends on their ability first to mobilize initial user networks and then to maintain users' active participation and ensure growth of the user base sufficient for sustainable revenue generation (Constantiou et al., 2016). We investigate the case of Airbnb and Couchsurfing, which is the mainstream of home sharing. Airbnb and Couchsurfing are sharing platforms network in the home sharing industry. Our study is about examine public sentiments on these home-sharing companies. We could find public positive and negative emotion about Airbnb and Couchsurfing in Twitter from 2010 to 2017. We discover the different characteristics and identify the historical Changes of tweets. Using UCINET, the authors analysis the betweenness centrality and visualizing semantic network based on multidimensional scaling(MDS). Our study provides public perceptions of home sharing industry through comparing Airbnb and Couchsurfing.

\section{LITERATURE REVIEW}

\subsection{Airbnb}

Airbnb is an online community for vacation rentals that allows travelers and accommodation providers to list, find and rent lodging. Airbnb was founded in 2008 in San Francisco. With the increasing demands in travel accommodation, the company discovered the great potential of this market; thus, Airbnb was then created to provide low-cost and unique travel experience to capture the market demand. Airbnb has focused on the economic impact they can bring internationally and endeavors to align it with the goal of maintaining the current development in the neighborhoods in which they operate. On average, Airbnb generated more than $\$ 300$ million in economic activity in several major cities, such as New York, Paris, Berlin, and London (Chan et al., 2016).

\subsection{Couchsurfing}

Couchsurfing is a non-profit organization that 'seeks to internationally network people and places, create educational exchanges, raise collective consciousness, spread tolerance and facilitate cultural understanding' (Couchsurfing, 2006). The project was originally launched in 2003 (Molz \& Jennie Germann, 2013). This community works on the premise that a user has potential friends around the world. These friends are hosts who are willing to let a stranger sleep over at their home rather than staying at a hotel. People can find hosts and share their experiences via the website, which is made up of a community of 10 million people in 200,000 cities (Global Investor, 2015).

\subsection{Applicable theory}

The authors found applicable theories for applying the results.

\section{Cognitive dissonance theory}

"Dissonance is aroused whenever a person engages in an unpleasant activity to obtain some desirable outcome. From the cognition that the activity is unpleasant, it follows that one would not engage in the activity; the cognition that the activity is unpleasant is dissonant with engaging 
in the activity. Dissonance should be greater, the greater the unpleasant effort required to obtain the outcome." (Harmon-Jones \& Mills, 1999)

Consider someone who stays an expensive Airbnb house but discovers that it is not comfortable to stay long. Dissonance exists between their beliefs that they have paid a good Airbnb house and that a good house should be comfortable. Dissonance could be eliminated by deciding that it does not matter since the house is mainly used for short trips (reducing the importance of the dissonant belief) or focusing on the house's strengths such as safety, appearance (thereby adding more reasonable beliefs). Thus people can rationalize their conduct by thinking so.

\subsection{Mere exposure effect}

The mere exposure effect is a psychological phenomenon by which people tend to develop a preference for things or people that are more familiar to them than others. Repeated exposure increases familiarity. This effect is therefore also known as the familiarity effect. Therefore misattribution of positive feelings (due to fluency) to the ad or brand comes into effect. This means that with mere exposure the more often you see an information the better you can process it and the more fluent it is. Human beings like easy processing rather than difficult cognitive processes so they stick with familiar things. This may be the explanation for their positive feelings towards an ad or brand (Falkenbach et al., 2013). When people evaluate Airbnb and Couchsurfing, there are many factors why people evaluate that way. Among them, mere exposure effect theory can be a factor. We can see Airbnb's commodity advertisement a lot more than Couchsurfing. Through the advertisement, people are exposed several times with Airbnb, and it affects raising people's positive evaluation about Airbnb because of the familiarity that improved by exposure.

\subsection{Research questions}

RQ 1. Semantic Networks. In the datasets from tweets "Airbnb" and "Couchsurfing", what were the different characteristics discovered?

RQ 1-1. In view of word usage frequency, centrality and semantic networks, what were the characteristics found in tweets about "Airbnb" and "Couchsurfing" respectively?

RQ 1-2.As time went by, what were the remarkable differences discovered from tweets about "Airbnb" and "Couchsurfing" respectively?

RQ 2. What are the theoretical and practical implications of the study's findings?

\section{METHODS}

\subsection{Data gathering}

The datasets were retrieved from Twitter by using Python. We gathered past tweets from Twitter through a python library. Twitter is an online news and social networking service which users post and interact with messages, and it is frequently used by the general public. In addition, to investigate how the home-sharing industry has developed since related enterprises showed up, we used two keywords, "Airbnb" and "Couchsurfing", which are two representative companies in the home-sharing industry. The time periods of datasets were divided into four groups respectively: before 2015(2010-2014), 2015, 2016 and 2017. 


\subsection{Semantic network analysis}

This study employed semantic network analysis (SNA), which is a numerical and graphical measurement method for a variety of text data. Semantic network analysis is a semi-automated text analysis for determining the most frequently used words and the differences among texts in terms of word frequency and clusters (Lee, Kim, \& Rosen, 2009; Doerfel \& Barnett, 1999). Python was employed for collecting data from Twitter. 'WORDij' (Danowski, 2010) was also employed to convert text data from Twitter, into co-occurrence matrices. 'WORDij' is word-pair based software for semantic structure retrieval without any prior categories (Danowski, 2010). Moreover, according to Danowski(2010), word pairs are made based on word proximity which is calculated by a "window that slides through the text, counting all word pairs inside as it moves from word in the full text". For calculating betweenness centrality and visualizing semantic network based on multidimensional scaling (MDS), we used UCINET6 for calculating centrality from co-occurrence matrix. Besides, we also used NETDRAW, which is embedded from UCINET6, for drawing semantic network based on co-occurrence matrix and centrality.

\section{RESULTS}

Table 1 indicates top 20 words based on frequency and betweenness centrality from the data sets (Tweets gathered from Twitter based on keyword 'airbnb' from 2010to 2017). In the first period (before 2016) 'airbnb', 'uber', 'travel', 'sharing',' business', 'economy' locate at top 6 words in order of frequency. Because 'airbnb' is the search keyword of data collecting process, it always locates at the first order on tables of frequency and centrality. 'uber' has the second highest order at both frequency and centrality. In the second period (2016) 'airbnb', 'uber', 'travel', 'sharing', business', 'economy' locate at top 6 words in order of frequency, and 'airbnb', 'app', 'travel', 'ceo', 'twitter', 'uber' locate at top 6 words based on betweeness centrality. In the third period (2017) 'airbnb', 'travel', 'hosts', 'first', 'hi', 'dm'(direct message) locate at top 6 words by frequency, and 'airbnb', 'first', 'dm' (direct message), 'help', 'users', 'man' locate at the upper 6 words based on centrality. Table 2 indicates the upper 20 words based on frequency and betweeness centrality from the data sets (Tweets gathered from Twitter based on keyword 'couchsurfing' from 2010 to 2017). In the first period (before 2016) 'couchsurfing', 'travel', 'site', 'people', 'airbnb', 'moscow' list on the table from the highest frequency to 6th highest frequency, and 'couchsurfing', 'data', 'tour', 'business', 'check', 'app' locate at top 6 highest centrality. In the second period (2016) 'couchsurfing', 'travel', 'moscow', 'host', 'airbnb', 'world' locate at top six based on frequency, and 'couchsurfing', 'people', 'lot', 'better', 'Italian', 'trvel', list on table 3 based on centrality order.

Figure 1 is about semantic network of Airbnb from Twitter. 'uber', 'sharing', and, 'economy' have high frequency and betweenness centrality. There are many names of cities such as 'Amsterdam', 'San Francisco', 'New York' in the network. There are words related to a case of hidden camera issue such as 'german', 'hidden', 'camera', 'suing'. In 2015, a german woman argued that she was unaware of the camera, which allegedly captured both naked footage and private conversations. In addition, there are four clusters: the first cluster (A) is about 'Airbnb'relevant issues; the second cluster (B) stands for user experience on mobile app and web site; the third cluster (C) is about trip-relevant startups; the fourth cluster (D) describes car-sharing industry (Uber). 
Table 1. Frequency and centrality of 'Airbnb' data from 2010 to 2017.

\begin{tabular}{|c|c|c|c|c|c|c|}
\hline & \multicolumn{2}{|c|}{ 2010-2015 } & \multicolumn{2}{c|}{ 2016 } & \multicolumn{2}{c|}{2017} \\
\hline Airbnb & Frequency & Centrality & Frequency & Centrality & Frequency & Centrality \\
\hline 1 & airbnb & airbnb & airbnb & airbnb & airbnb & airbnb \\
\hline 2 & uber & Uber & travel & app & travel & first \\
\hline 3 & travel & Mashable & ceo & travel & hosts & dm \\
\hline 4 & sharing & Birdbnb & twitter & ceo & first & help \\
\hline 5 & business & Money & uber & twitter & hi & users \\
\hline 6 & economy & Sharing & bitcoin & uber & dm & man \\
\hline 7 & stay & Economy & needs & bitcoin & study & Managed \\
\hline 8 & hosts & tech & bookings & most & reject & hear \\
\hline 9 & love & Order & grow & users & guests & Code \\
\hline 10 & company & trip & full-fledged & chesky & email & Study \\
\hline 11 & amsterdam & business & hub & gift & help & Case \\
\hline 12 & hotel & amsterdam & hosts & business & thanks & Interiordesign \\
\hline 13 & startup & hosts & app & housing & stay & Baboons \\
\hline 14 & apartment & share & rent & customers & business & Disabilities \\
\hline 15 & place & site & stay & start & rent & Reject \\
\hline 16 & san & mobile & hotel & hosts & finds & People \\
\hline 17 & klm & hotel & business & tenants & disabilities & travel \\
\hline 18 & tourist & host & first & hub & trip & Hosts \\
\hline 19 & nyc & app & updates & grow & people & Business \\
\hline 20 & rent & people & front & Full- & love & Email \\
\hline
\end{tabular}

Table 2. Frequency and centrality of 'Couchsurfing' data from 2010 to 2017.

\begin{tabular}{|c|c|c|c|c|c|c|}
\hline & \multicolumn{2}{|c|}{ 2010-2015 } & \multicolumn{2}{c|}{ 2016 } & \multicolumn{2}{c|}{2017} \\
\hline Couchsurfing & Frequency & Centrality & Frequency & Centrality & Frequency & Centrality \\
\hline 1 & couchsurfing & couchsurfing & couchsurfing & couchsurfing & couchsurfing & couchsurfing \\
\hline 2 & travel & Data & travel & people & travel & Travel \\
\hline 3 & site & Tour & moscow & lot & host & Airbnb \\
\hline 4 & people & Business & host & better & traveling & City \\
\hline 5 & airbnb & Check & airbnb & italian & experience & Host \\
\hline 6 & moscow & app & world & Travel & airbnb & Experience \\
\hline 7 & check & Her & people & Italy & first & Traveler \\
\hline 8 & great & Shes & italian & Couches & people & First \\
\hline 9 & host & Building & site & Policeman & ttot & tot \\
\hline 10 & website & Ever & first & Rape & friends & Added \\
\hline 11 & love & Hook-up & couch & Site & moscow & Ways \\
\hline 12 & friends & travel & photo & Host & great & People \\
\hline 13 & time & use & great & World & check & Best \\
\hline 14 & thanks & sharing & friends & Moscow & best & Why \\
\hline 15 & chrome & management & journey & Airbnb & free & Youtube \\
\hline 16 & app & brand & time & First & world & Casey \\
\hline 17 & couch & fail & round & Website & time & free \\
\hline 18 & good & poor & experience & Women & meet & Fenton \\
\hline 19 & android & kill & photographers & Accused & couch & Friends \\
\hline 20 & cs & airbnb & sleep & News & love & Fiona \\
\hline
\end{tabular}




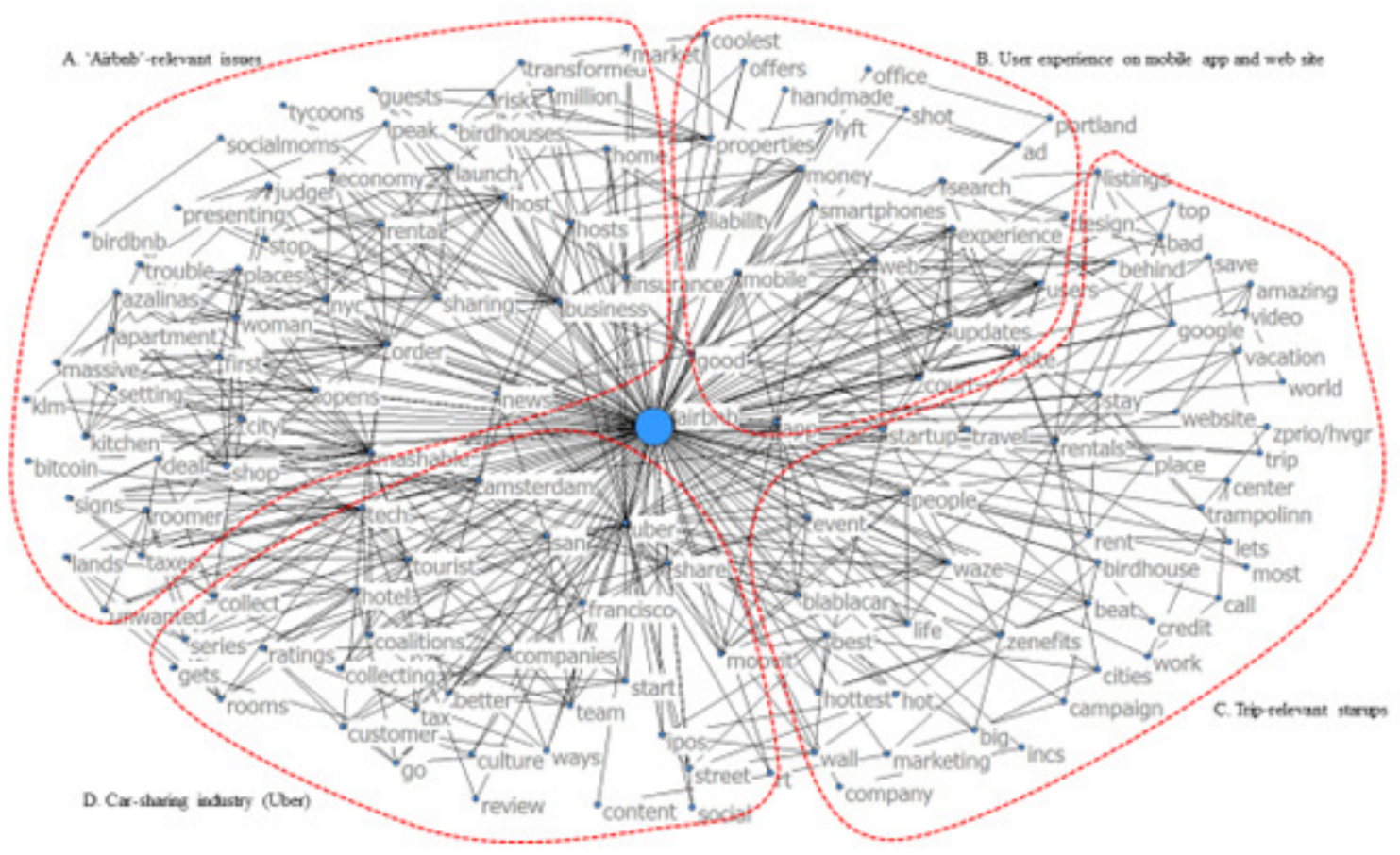

Figure 1. Semantic Network from Twitter on ‘Airbnb’ from 2010 to 2015

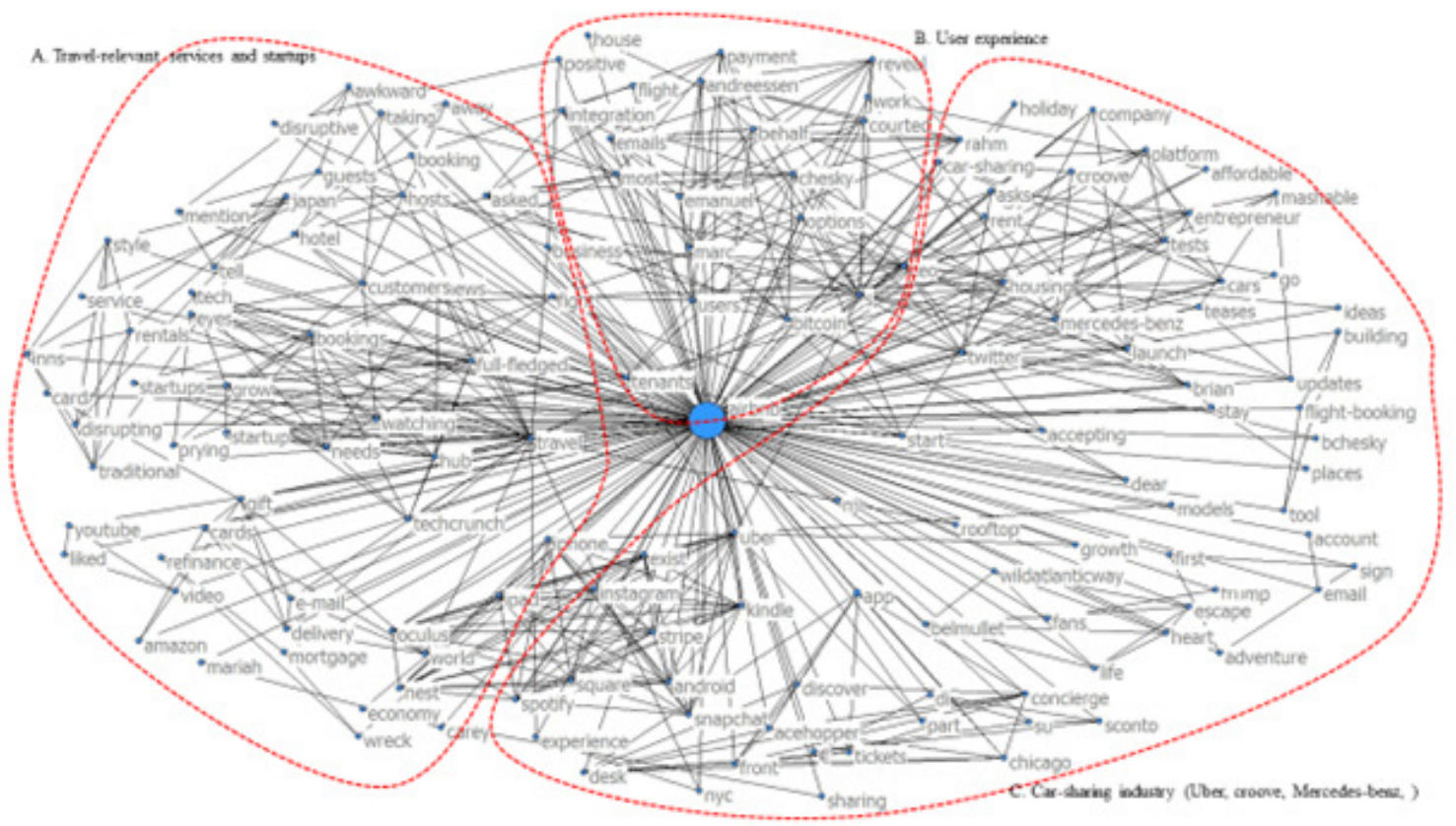

Figure 2. Semantic Network from Twitter on 'Airbnb' in 2016 
There are words relevant to a suit case about contract on lease of apartment such as 'tenants', 'fights' in Figure 2. There are words about blockchain technology such as 'bitcoin'. There are three clusters: the first cluster (A) depicts travel-relevant services and starups; the second cluster (B) stands for user experience; the third cluster (C) is about car-sharing industry (Uber, Crrove, Mercedes-benz).

There are words about discrimination on disabilities from academia such as 'disabilities', 'researchers', 'study' in Figure 3. There are three clusters: the first cluster (A) describes houserelevant comments (interior design, architecture, decoration); the second cluster (B) stands for 'Airbnb'-relevant issues including enter china market; the third cluster $(\mathrm{C})$ is about travelrelevant reports and perception.

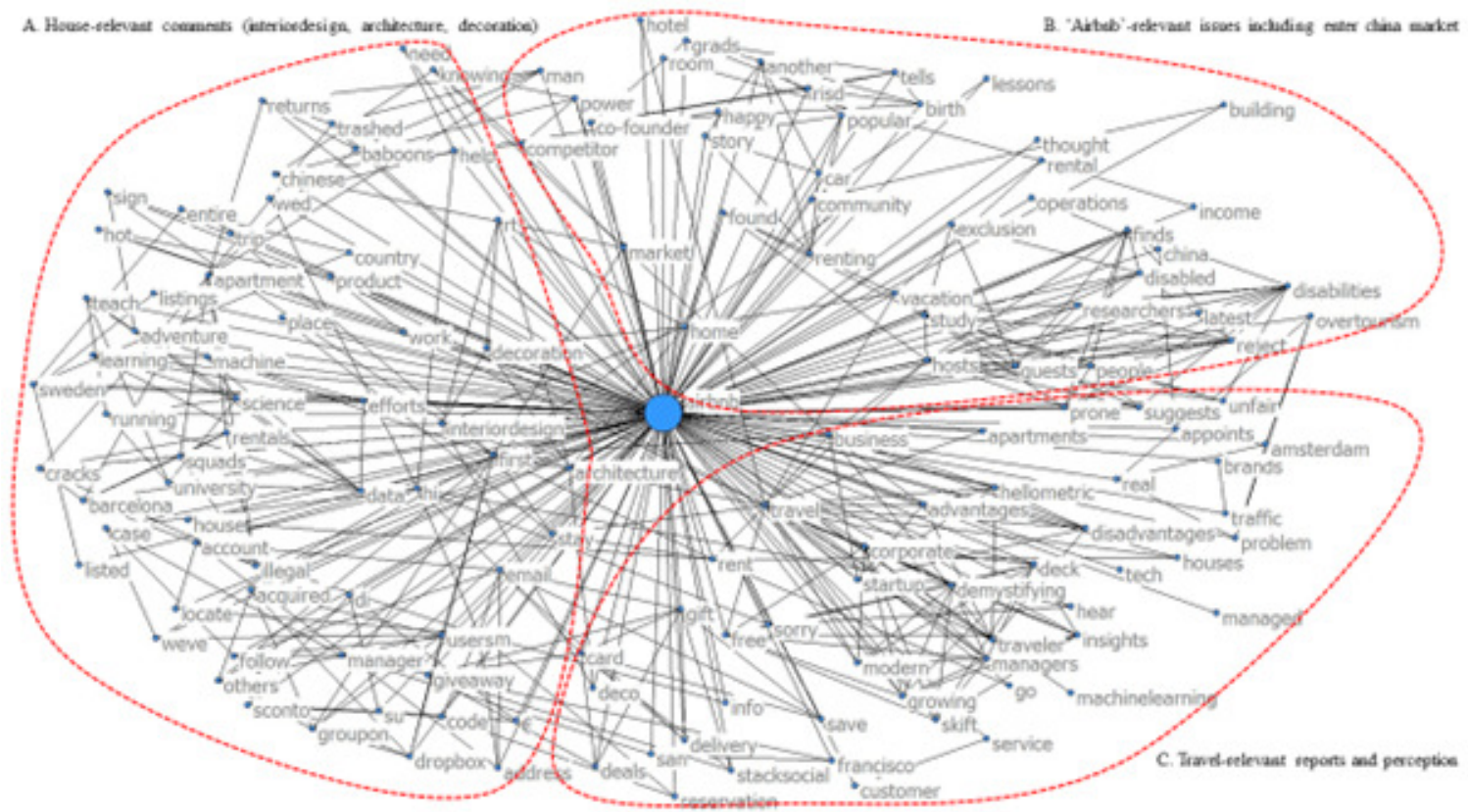

Figure 3. Semantic Network from Twitter on 'Airbnb' in 2017

There are words related to sex culture such as 'hook-up', 'secret', 'sex' in Figure 4. There are names of cities such as 'Moscow', 'San Francisco', 'Amsterdam'. There are three clusters: the first cluster (A) is about violence-relevant news; the second cluster (B) describes user experience (os, android, site, apps, web, etc.); the third cluster (C) stands for Competitors and other starups.

The word 'ttot' is abbreviation of 'Travel Talk on Twitter'. There are words related to a murder case in Nepal such as 'Nepal', 'American', 'murdered' in Figure 5. There are three clusters: the first cluster (A) depicts travel-relevant issues; the second cluster (B) is about violence-relevant news; the third cluster $(\mathrm{C})$ stands for competitors and other startups.

There are many words relevant to travel experience such as 'experience', 'thailand', 'sudan', 'cambodia', 'iran', 'toronto', 'quebec', 'san francisco', 'europe', 'russia' in Figure 6. There are three clusters: the first cluster (A) describes travel experiences; the second cluster (B) is about violence-relevant news; the third cluster (C) stands for competitors-relevant issues. 


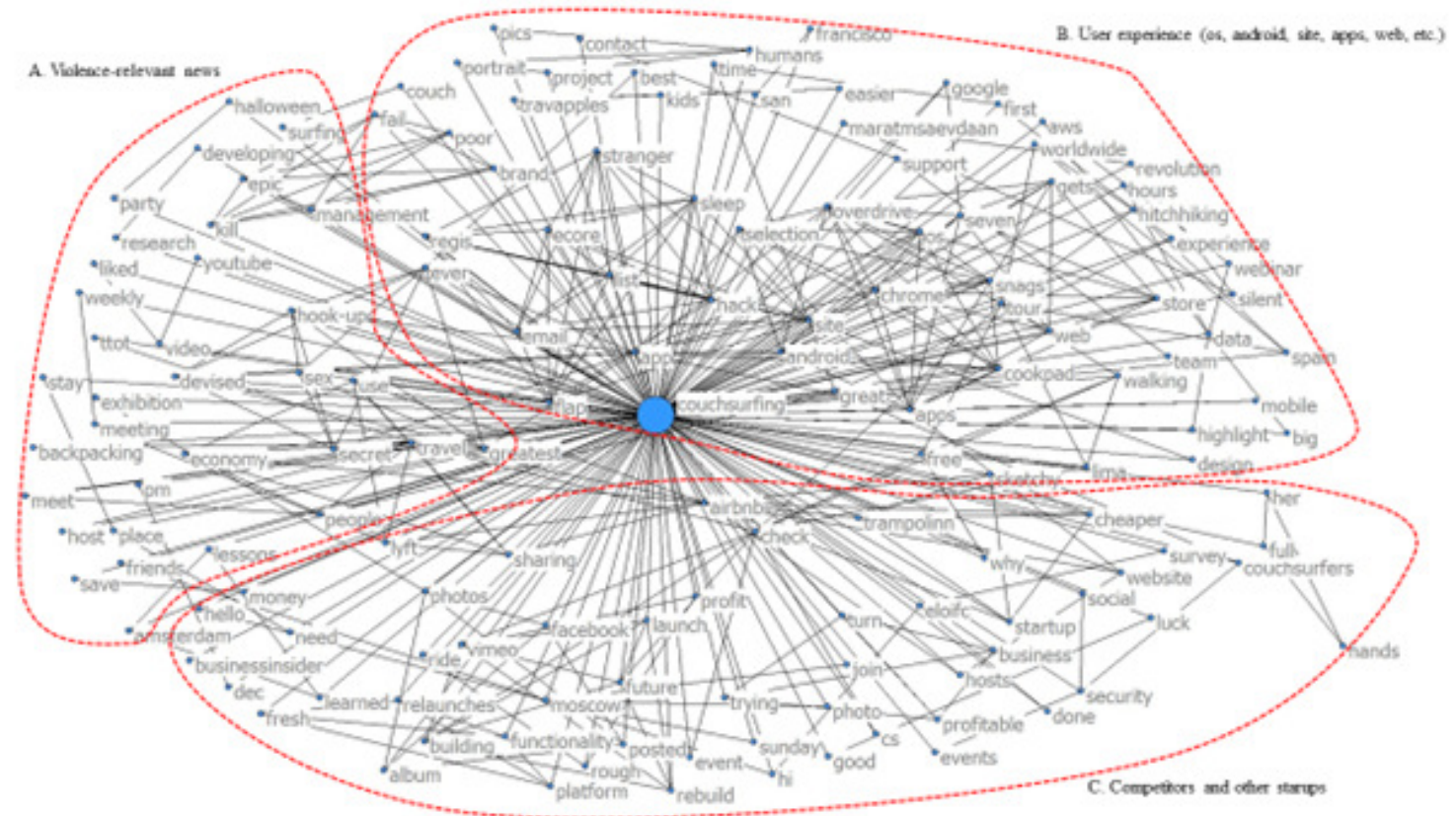

Figure 4. Semantic Network from Twitter on 'Couchsurfing' from 2010 to 2015

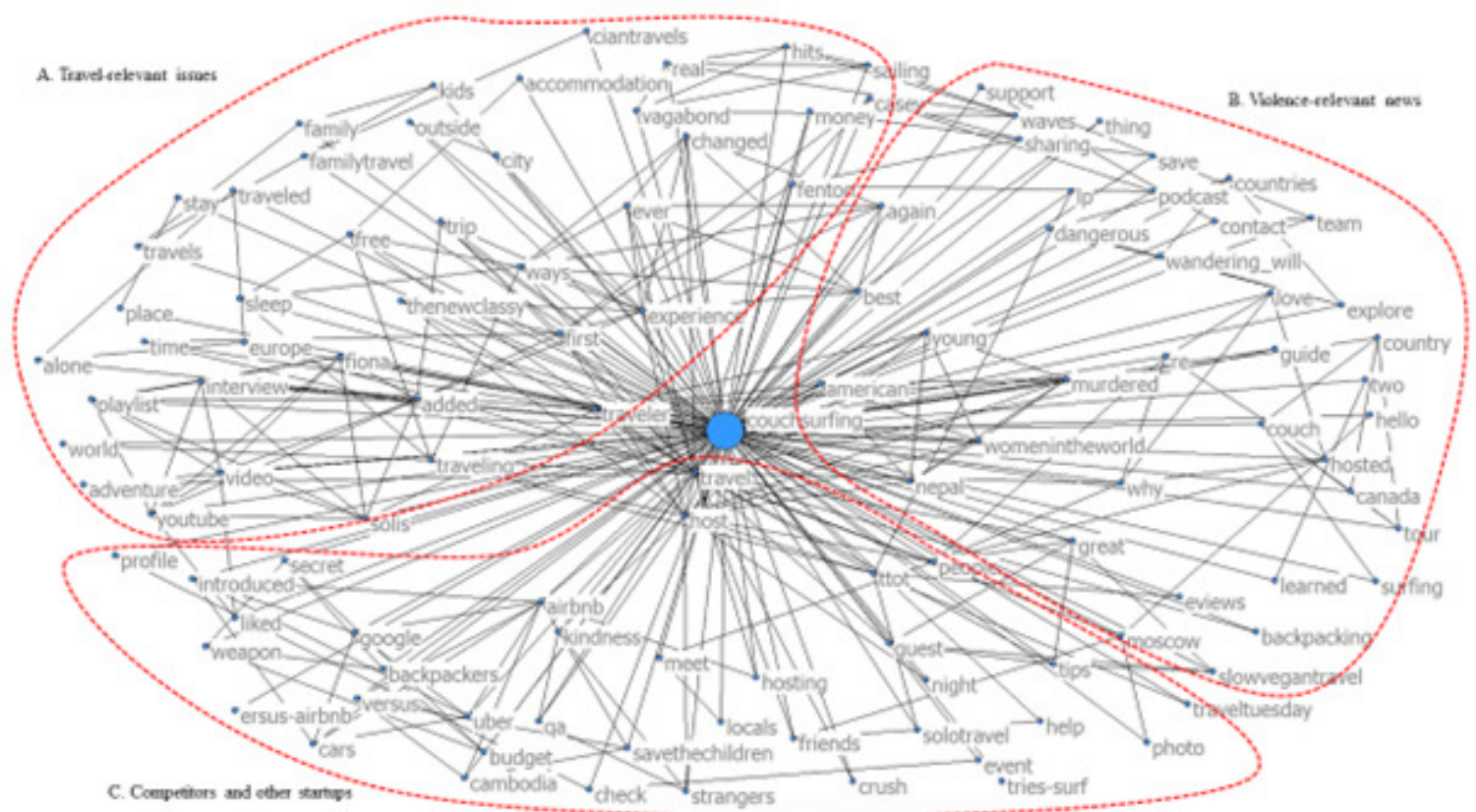

Figure 5. Semantic Network from Twitter on 'Couchsurfing' in 2016 


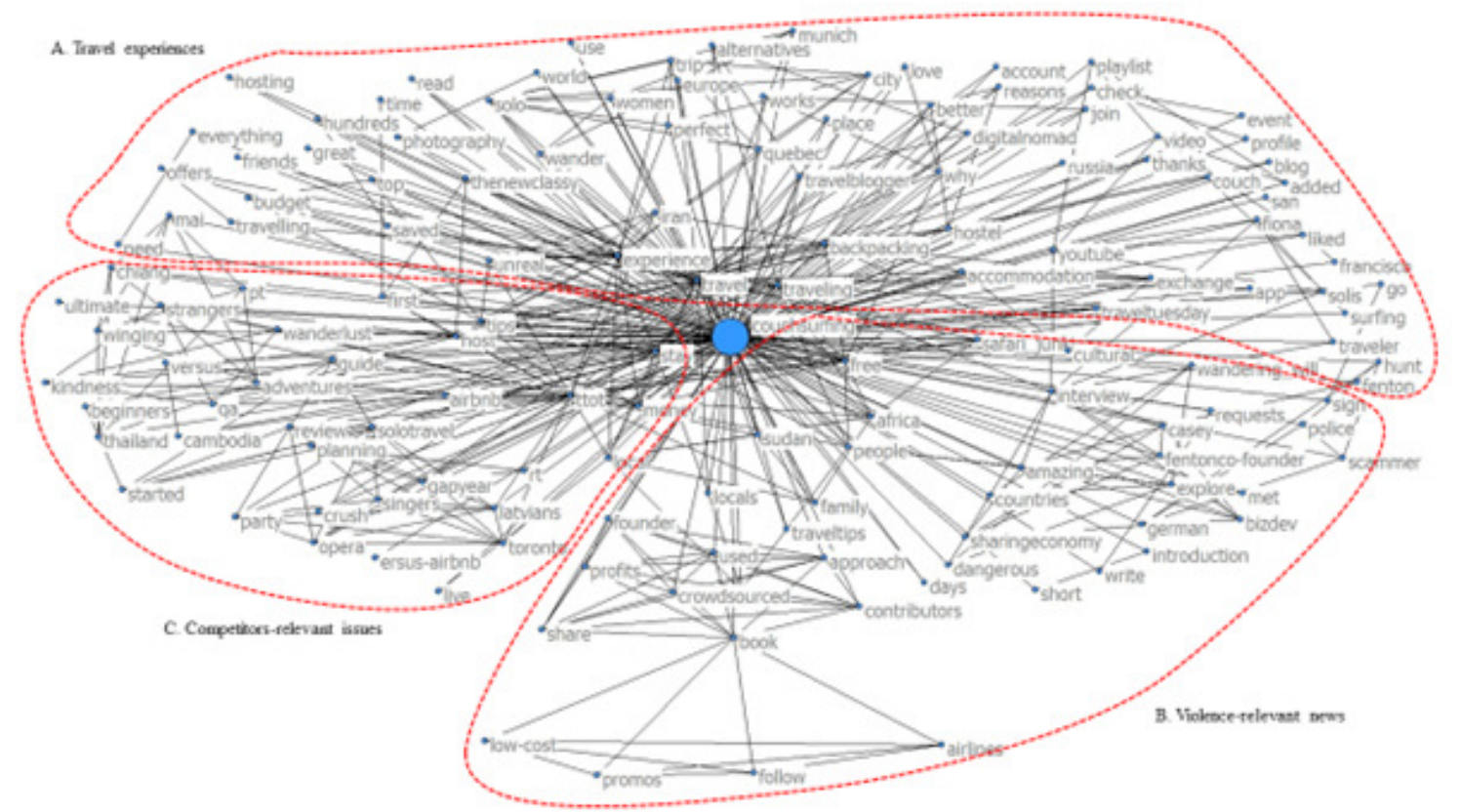

Figure 6. Semantic Network from Twitter on 'Couchsurfing' in 2017

\section{CONCLUSiOnS}

By analysing the semantic networks of text data from Twitter and the words which have high frequency and centrality in the networks from four different time periods, the current study seeks to figure out how home sharing economy change over time from early stage to 2017. In most semantic networks in this study, some kind of flash and horrible event including murder or sexual assault cases has been mentioned frequently. As a result, their frequency and centrality are high. In the semantic networks from keyword 'airbnb', 'uber' appears frequently, because 'uber' is another popular sharing economic service for travelling. In the networks from search keyword 'couchsurfing', 'airbnb' has often been mentioned, because 'airbnb' service hosts can provide their houses to travelers for 'couchsurfing'. Since 2016 the word 'Youtube' has been mentioned frequently than ever in the networks on 'couchsurfing'. Perhaps a lot of couchsurfing hosts make Youtube main advertisement tools. Additionally, there are more violence-relevant issues about 'couchsurfing' than 'airbnb'.

Time span of data from twitter in this study is not that large enough to cover the development periods of Airbnb and couchsurfing. In addition, Twitter is not only one representative social media website so that the dataset of universality had limitations. For further development, time span of data should expand to around 10 years ago. The variety of data sources should be used by not only twitter but also facebook, reddit and other popular social media websites. Deep Learning method based on Natural Language could develop Semantic Network Analysis including clustering and categorizing data set. (e.g., Deep Learning Open Source including Google Tensor Flow, etc). Innovation theories including 'Diffusion of innovation theory' could be employed in the further study. 


\section{REFERENCES}

[1] Belk, Russell. "You are what you can access: Sharing and collaborative consumption online." Journal of Business Research 67.8 (2014): 1595-1600.

[2] Borgatti, S. P., Everett, M. G., \& Freeman, L. C. (2002). UCINET 6 for Windows. Harvard: Analytic Technologies, 185.

[3] Borgatti, S. P. (2005). Centrality and network flow. Social networks, 27(1), 55-71.

[4] Chan, Cheuk, et al. "BUSINESS 478 SECTION E200." (2016).

[5] Constantiou, Ioanna, Ben Eaton, and Virpi Kristiina Tuunainen. "The Evolution of a Sharing Platform into a Sustainable Business." System Sciences (HICSS), 2016 49th Hawaii International Conference on. IEEE, 2016.

[6] CouchSurfing Project Web 2.0 (2006) Our Mission. Available at: http://www.couchsurfing.com/ mission.html (consulted November 2008).

[7] Danowski, J. A. (2010). WORDij 3.0 [computer program]. Chicago: University of Illinois at Chicago.

[8] Doerfel, M. L., \& Barnett, G. A. (1999). A semantic network analysis of the International Communication Association. Human communication research, 25(4), 589-603.

[9] Falkenbach, Katja, et al. "Mere Exposure Effect." (2013).

[10] Freeman, L. C. (1977). A set of measures of centrality based on betweenness. Sociometry, 35-41.

[11] Hamari, Juho, Mimmi Sjöklint, and Antti Ukkonen. "The sharing economy: Why people participate in collaborative consumption." Journal of the Association for Information Science and Technology 67.9 (2016): 2047-2059.

[12] Harmon-Jones, Eddie Ed, and Judson Ed Mills. "Cognitive dissonance: Progress on a pivotal theory in social psychology." Scientific Conferences Program, 1997, U Texas, Arlington, TX, US; This volume is based on papers presented at a 2-day conference at the University of Texas at Arlington, winter 1997.. American Psychological Association, 1999.

[13] Lee, S., Hyun Kim, J., \& Rosen, D. (2009). A semantic network and categorical content analysis of Internet and online media research. The Open Communication Journal, 3(1).

[14] Molz, Jennie Germann. "Social networking technologies and the moral economy of alternative tourism: The case of couchsurfing. org." Annals of tourism research 43 (2013): 210-230.

[15] Saussier, Julie. "Sharing as a disruptive force" Global Investor Nov. 2015: 18. Print.

[16] Xinyuea, Zhu, and Guo Rongb. "SHARING ECONOMY." (2016)

[17] “PEER NETWORKS ARE CONNECTING THE DOTS” Global Investor Nov. 2015: 2. Print

[18] “THE SHARING MARKETPLACE: BRIDGING INTERESTS, COUNTRIES AND AGES” Global Investor Nov. 2015: 32. Print. 


\section{AUTHORS}

JinTao Huang

Master of interaction science, SungKyunKwan University

KangNyeon Yi

Ph.D of interaction science, SungKyunKwan University

JiHye Han

Master of interaction science, SungKyunKwan University 